\title{
Effect of Glass Fibers on Self Compacting Concrete
}

\author{
Sandeep L. Hake', S. S. Shinde ${ }^{\text {, Piyush K. Bhandari }{ }^{1} \text {, P. R. Awasarmal }{ }^{2} \text {, B. D. Kanawade }}$ \\ ${ }^{1}$ Department of Civil Engineering, DVVP College of Engineering, Ahmednagar, Maharashtra (India). \\ ${ }^{2}$ Dept. of Civil Engineering, G.S. Mandal's Maharashtra Institute of Technology, Aurangabad, Maharashtra (India).
}

\begin{abstract}
Self Compacting Concrete (SCC) is a specially developed concrete for concreting under extreme condition of inaccessibility from heights. It is capable to flow under influence of its own weight. It could be used when encountered with dense reinforcement and complex structural design. Problem of segregation as well as bleeding is eliminated and vibration is not required for compaction. As concrete is strong in compression and weak in tension. Hence to make it strong in tension, discontinuous Anti-Crack high dispersion glass fibers are added. SCC mix prepared with addition of discontinuous glass fibers is called as Glass Fiber reinforced Self Compacting Concrete (GFRSCC). In this paper an experimental study has been carried out to check the effect of Anti-Crack high dispersion glass fibers on the compressive strength, split tensile strength and flexural strength of SCC. The result show that, as compared to the Normal SCC, the compressive strength of GFRSCC increases by $2.80 \%$ and $12.42 \%$, the split tensile strength of GFRSCC increases by $4.47 \%$ and $25.12 \%$ and the flexural strength of SCC increases by $6.57 \%$ and $14.34 \%$ when the Cem-FIL Anti-Crack HD glass fibers were added as $0.25 \%$ and $0.50 \%$ respectively by the weight of total cementitious material contents. The addition of $0.25 \%$ Cem-FIL Anti-Crack HD glass fibers to SCC has not much affect on the workability of Normal SCC. Whereas, addition of $0.50 \%$ Cem-FIL Anti-Crack HD glass fibers reduces the workability of SCC.
\end{abstract}

\section{Introduction}

Today Self Compacting concrete (SCC) has proven to be a big milestone in the construction industry because of its advantages. It can pass easily through congested reinforcement and the gap between formwork and steel reinforcement, also capable to fill the formwork without any voids. It is common experience that, dense reinforcement causes problems during pouring and compaction of concrete. Therefore, concrete must be capable enough to pass through the dense reinforcement arrangement without blocking or segregating. Also poor placement and the lack of compaction can lead to the inclusion of voids and loss of long term durability of concrete structures. To avoid this concrete capable enough to flow by itself and filling the spaces should be used. And this need has been solved by introduction of SCC. It is superior over normal vibrated concrete as it eliminates requirement of vibration for compaction of concrete, thus the reduction in noise at construction site is achieved. It also gives better surface finish. Due to high workability, it is easier to place SCC, thereby reducing the number of workers on site. It increases construction speed leading to economy. Since SCC requires more amount of binder and to achieve economy, cement is replaced in percentage by cement replacement materials like fly ash, GGBS, silica fume, etc $[1,2,3]$.

In 1980's, Japan encountered shortage of construction workers. To overcome this problem, Okamura from Japan proposed necessity of SSC as an effective solution for labour intensive concreting work. SSC was superior to normal cement concrete in terms of properties in fresh state as filling ability, ease in passing and segregation resistance. To prepare SSC mix, cement paste content has to be increase, coarse aggregate content and water-powder ratio must be reduced. To compensate these changes suitable admixture, preferably Superplasticizer is added [2]. Prepared SSC mixture is checked as per EFNARC guidelines for fresh concrete properties. Tests like Slump flow test, $\mathrm{T}_{50}$ slump flow, L-box test, V-funnel test and $\mathrm{V}$ - Funnel at $\mathrm{T}_{5 \text { minutes }}$ are

*Corresponding author: drsandiphake@gmail.com 
performed to comment on workability of SSC mix [3].

Concrete is considered strong in compression by assessing its high compressive strength. But at the same time it is weak in tension and shows brittle nature. Hence fibre reinforced composite (FRC) were incorporated to solve this issue within concrete [4]. Different types of fibers like steel, glass, asbestos, polypropylene etc are already used in concrete to get fiber reinforced concrete. Addition of fiber helps to arrest the development of cracks and improve modulus of elasticity of composite material. Since load carrying capacity is improved, tensile strength also found to have increased. Fibers helped to improve toughness, tensile and flexural strength also reduce cracks and shrinkage in concrete.

Present investigation was carried to study outcomes of glass fiber addition in normal SSC mix. Discontinuous Cem-FIL Anti-Crack High Dispersion glass fibers were added in percentage by weight of cementitious material to normal SCC mix. Past investigation showed glass fibers addition increases ductility of mix [5, 6]. Also reduction in crack length and total cracked area observed due to early age shrinkage in composite mix. By performing workability test, performance of fresh prepared GFRSCC is investigated. Properties of hardened concrete upon fiber addition must provide glimpse about performance of GFRSCC mix in long run. Plot of load versus deflection values during flexural strength test will provide behaviour of beam specimen cast from normal SCC and GFRSCC under applied point load. Aim is to investigate the effect of glass fibers addition within normal SSC mix.

\section{Literature Review}

Concept and inception of SCC was done in 1986 by Okamura in Japan. Since then number of researchers has contributed in enhancing properties of SCC. Noticeable amongst them were studied and their findings are considering for improving workability as well as strength properties. Addition of fibers also contributed in increasing the compressive, split tensile strength and flexural strength of SCC.

Nan Su et al. [5] developed mix design method which was found to be more economical and easy to use as compared to conventional Japanese mix design method. The Packing Factor (PF) parameter was adopted which has influenced workability, durability and strength of SCC mix. Author adopted PF values in gradual decreasing order from 1.18, 1.16, 1.14 and 1.12. On reducing PF value in SCC mix compressive strength was found to be enhanced from 27.5 to 48
$\mathrm{MPa}$. Requirement of cement binder was reduced upto $424 \mathrm{~kg} / \mathrm{m}^{3}$ as compared to previous requirement of $500 \mathrm{~kg} / \mathrm{m}^{3}$. Even workability and durability was improved by using optimum content of Packing Factor.

J. K. Su et al. [7] suggested SCC mix by varying sand ratio $(\mathrm{S} / \mathrm{A})$ in increasing order from $0.3,0.4,0.45$, $0.475,0.5,0.525$, and 0.55 . It showed increase in workability upon increase in S/A ratio. Also rheological properties were enhanced. Optimum S/A ratio recommended were upto $47.5 \%$. Investigation also revealed that $\mathrm{S} / \mathrm{A}$ ratio has negligible effect on elastic modulus of SCC.

T. Suresh Babu et al. [8] prepared glass fibre reinforced self compacting concrete (GFRSCC) by adding $600 \mathrm{gm} / \mathrm{m}^{3}$ of Cem-FIL Anti-Crack High Dispersion glass fibers along with suitable admixtures. SSC mix was prepared as per Nan-Su method mix design steps and Okamura's guidelines. By adding fibers, prepared GFRSCC showed increase in compressive strength, split tensile strength and flexural strength by 2.0 to $5.5 \%, 3.0$ to $7.0 \%$ and 11.0 to $20.0 \%$ respectively. Ductility, Energy absorption capacity, Secant modulus of modified SCC was also improved.

M Chandrasekhar et al. [9] prepared M50 grade GFRSCC by adding glass fibers within normal SCC. By implementing different percentage of confinement in the form of hoop steel, showed increase in compressive strength from $7.25 \%$ to $44.30 \%$. Also values of Young's modulus increased owing due to confinement.

\section{Materials and Experimental work}

\subsection{Materials}

The ingredients used for making the SCC and GFRSCC are as follows.

3.1.1 Cement: The Ordinary Portland Cement (OPC) of 53 grade (Ambuja Cement) having specific gravity of 3.15 was used in study. It was tested to find physical properties in accordance with Indian Standard specifications.

3.1.2 Fly Ash: Locally available fly ash confirming to IS: 3812 (Part-1) -2013 [10].

3.1.3 GGBS: GGBS confirming to IS: $12089-1987$ having the surface area about 350 to $450 \mathrm{~m}^{2} / \mathrm{kg}$ was used [11].

3.1.4 Fine Aggregate: Natural River Sand, clear from all sorts of organic impurities was used. The fine aggregate passing through $4.75 \mathrm{~mm}$ sieve and 
having specific gravity of 2.70 and confirming zone II were used.

3.1.5 Coarse Aggregate: Crushed basalt angular aggregates passing from $12.5 \mathrm{~mm}$ sieve and confirming to IS: $383-2016$ and having specific gravity of 2.74 was used [12].

3.1.6 Water: Potable water is generally considered satisfactory for mixing concrete. Water free from acids, oils, alkalis, vegetables or other organic impurities is preferable for investigation. Ordinary tap water was used for preparing concrete mix.

3.1.7 Superplasticizer: The Superplasticizer Conplast SP 430 confirming to IS: 9103-1999 having specific gravity of 1.1 to 1.2 was used in this study [13].

3.1.8 Viscosity Modifying Agent: VMAMastermatrix 2 (Glenium Stream 2) having specific gravity of 1.19 was used in this study.

3.1.9 Glass Fibers: Cem-FIL Anti-Crack High Dispersion glass fibers were used for this experimental study. Table 1 provides information related to physical properties of fibers used in the investigation

Later activator solution added at gradual rate during continuous mixing to get desired mix.

Table 1. Properties of Cem-FIL Anti-Crack High Dispersion Glass Fibers

\begin{tabular}{|c|l|c|}
\hline $\begin{array}{c}\text { Sr. } \\
\text { No. }\end{array}$ & Property & $\begin{array}{l}\text { Typical } \\
\text { Value }\end{array}$ \\
\hline 1 & Number of Fibers & $\begin{array}{c}214 \\
\text { millions } / \mathrm{kg}\end{array}$ \\
\hline 2 & Aspect Ratio & $857: 1$ \\
\hline 3 & Specific Surface Area & $150 \mathrm{~m}^{2} / \mathrm{kg}$ \\
\hline 4 & Tensile Strength & $1700 \mathrm{MPa}$ \\
\hline 5 & Modulus of Elasticity & $72 \mathrm{GPa}$ \\
\hline 6 & Corrosion Resistance & Very High \\
\hline 7 & Specific Gravity & 2.68 \\
\hline 8 & Density & $26 \mathrm{kN} / \mathrm{m}^{3}$ \\
\hline 9 & Filament Diameters & $14 \mathrm{microns}$ \\
\hline 10 & Filament Length & $12 \mathrm{~mm}$ \\
\hline
\end{tabular}

\subsection{Mix Design Procedure for Normal SCC and GFRSCC}

As per literature study, in previous investigation SCC mix was prepared without performing mix design [14]. Whereas, in present study, ACI 237-2015 guidelines and IS-10262:2019, sec. 4, both were used to prepare mix design $[15,16]$. The proportion of materials required for M30 grade normal SCC mix is given in table 2 .

Table 2. Ingredients of SCC for M30 Grade.

\begin{tabular}{|c|c|c|c|}
\hline $\begin{array}{c}\text { Sr. } \\
\text { No }\end{array}$ & $\begin{array}{c}\text { Ingredients of } \\
\text { SCC }\end{array}$ & $\begin{array}{c}\text { Proportion } \\
\text { by Weight } \\
\text { of Cement }\end{array}$ & $\begin{array}{c}\text { Quantity } \\
\text { in }\left(\mathbf{k g} / \mathbf{m}^{\mathbf{3}}\right)\end{array}$ \\
\hline 1 & Cement & 1 & 325.68 \\
\hline 2 & Fly Ash & 0.3571 & 116.315 \\
\hline
\end{tabular}

\begin{tabular}{|c|c|c|c|}
\hline 3 & GGBS & 0.0714 & 23.263 \\
\hline 4 & Fine Aggregate & 3.1066 & 1011.77 \\
\hline 5 & $\begin{array}{c}\text { Coarse } \\
\text { Aggregate }\end{array}$ & 2.8421 & 794.96 \\
\hline 6 & Water & 0.5428 & 176.8 \\
\hline 7 & Superplasticizer & 0.0357 & 11.63 \\
\hline 8 & VMA & 0.0049 & 1.62 \\
\hline
\end{tabular}

\subsection{Mix Design Procedure and fiber dosage}

For making GFRSCC, the Cem-FIL Anti-Crack High Dispersion glass fibers were added in two different percentages as $0.25 \%$ and $0.50 \%$ by the weight of total cementitious materials content. Prepared modified SCC mix used to study the fresh and hardened properties of SCC. Workability of fresh prepared $0.25 \%$ GFRSCC was assessed using tests like, Slump flow by Abram's cone, $\mathrm{T}_{50 \mathrm{~cm}}$ slump flow, L-box test, $\mathrm{V}$-funnel test and $\mathrm{V}$-funnel at $\mathrm{T}_{5}$ minutes test. The flow tests values were satisfying as per EFNARC guidelines. Since mix design data for the $0.25 \%$ GFRSCC was similar to Normal SCC mix design data, the design was adopted for further assessment. In case of $0.50 \%$ GFRSCC, it was observed that workability is affected in some extent due to addition of $0.50 \%$ glass fibers. In order to achieve workability requirements, the Superplasticizer dose was increased from $2.5 \%$ to $2.55 \%$ keeping the VMA dose constant. The $0.50 \%$ GFRSCC was prepared using new mix design data and again workability tests were carried out. This new design data was then adopted for further assessment. Table 3 denotes the quantity of ingredients used for GFRSCC for different percentage combinations.

Table 3. Mix Design Data for Different GFRSCC Mixes of

\begin{tabular}{|c|c|c|c|c|}
\hline \multicolumn{5}{|c|}{ M30 grade } \\
\hline \multirow{2}{*}{$\begin{array}{l}\text { Sr. } \\
\text { No }\end{array}$} & \multirow{2}{*}{$\begin{array}{l}\text { GFRSCC } \\
\text { Contents }\end{array}$} & \multirow[t]{2}{*}{ Unit } & \multicolumn{2}{|c|}{ Quantity } \\
\hline & & & $\begin{array}{l}\text { For } \\
0.25 \% \\
\text { GFRSCC }\end{array}$ & $\begin{array}{l}\text { For } 0.50 \% \\
\text { GFRSCC }\end{array}$ \\
\hline 1 & Cement & $\mathrm{kg} / \mathrm{m}^{3}$ & 325.68 & 325.68 \\
\hline 2 & Fly Ash & $\mathrm{kg} / \mathrm{m}^{3}$ & 116.315 & 116.315 \\
\hline 3 & GGBS & $\mathrm{kg} / \mathrm{m}^{3}$ & 23.263 & 23.263 \\
\hline 4 & $\begin{array}{c}\text { Fine } \\
\text { Aggregate }\end{array}$ & $\mathrm{kg} / \mathrm{m}^{3}$ & 1011.77 & 1011.77 \\
\hline 5 & $\begin{array}{c}\text { Coarse } \\
\text { Aggregate }\end{array}$ & $\mathrm{kg} / \mathrm{m}^{3}$ & 794.96 & 794.96 \\
\hline 6 & Water & lit. $/ \mathrm{m}^{3}$ & 176.8 & 176.8 \\
\hline 7 & $\begin{array}{c}\text { Super- } \\
\text { plasticizer }\end{array}$ & $\mathrm{kg} / \mathrm{m}^{3}$ & 11.63 & 11.86 \\
\hline 8 & VMA & $\mathrm{kg} / \mathrm{m}^{3}$ & 1.62 & 1.62 \\
\hline 9 & $\begin{array}{c}\text { Cem-FIL } \\
\text { Anti-Crack } \\
\text { HD Glass } \\
\text { Fibers }\end{array}$ & $\mathrm{kg} / \mathrm{m}^{3}$ & 1.163 & 2.326 \\
\hline
\end{tabular}




\section{Results and Discussions}

The workability tests were carried on the Normal SCC and GFRSCC mixes. The cubes, cylinders and beams were cast for Normal SCC and GFRSCC mixes and were tested for the compressive strength, split tensile strength and flexural strength respectively.

\subsection{Fresh Properties of Normal SCC and GFRSCC Mixes.}

The workability test were performed on the fresh Normal SCC and GFRSCC. The test results for flow values are given in Table 4 . It was evident from flow test that there is decrease in workability with addition of glass fibers. In case of $0.50 \%$ GFRSCC mix, workability was improved by adjusting the dosage of Superplasticizer. Even on assessing $\mathrm{T}_{50 \mathrm{~cm}}$ time, shows more time is required for spreading of fresh concrete. Thus, fiber addition reduces workability and makes concrete more stiff. Flow value in L-box test showed decrease in workability on addition of fibers. Vfunnel test was performed on normal as well as GFRSCC. For GFRSCC, with increase in percentages of fibers as $0.25 \%$ and $50 \%$, more time was required for concrete to flow out of funnel. $\mathrm{T}_{5 \text { minutes }}$ measured in seconds showed same nature for GFRSCC mix.

Table 4. Fresh Properties of Normal SCC and GFRSCC Mixes

\begin{tabular}{|l|l|l|l|}
\hline \multirow{2}{*}{ Test } & \multicolumn{3}{|l|}{ Mix Designation } \\
\cline { 2 - 4 } & $\begin{array}{l}\text { Normal } \\
\text { SCC }\end{array}$ & $\begin{array}{l}\text { 0.25\% } \\
\text { GFRSCC }\end{array}$ & $\begin{array}{l}\mathbf{0 . 5 0 \%} \\
\text { GFRSCC }\end{array}$ \\
\hline 1)Slump Flow Test & 681 & 676 \\
\hline $\begin{array}{l}\text { a) Horizontal } \\
\text { Flow in mm }\end{array}$ & 689 & 4 & 4 \\
\hline $\begin{array}{l}\text { b)T } \text { T }_{\text {cm time in }} \\
\text { sec }\end{array}$ & 3 & 0.85 & 0.84 \\
\hline 2) L-Box Test & 0.86 & 9 & 9 \\
\hline 3) V-Funnel Test & 8 & & \\
\hline $\begin{array}{l}\text { a)Time for } \\
\text { complete } \\
\text { discharge in } \\
\text { sec }\end{array}$ & & 10 & 11 \\
\hline b)T5 time in sec & 9 & & \\
\hline
\end{tabular}

\subsection{Hardened Properties of SCC and GFRSCC}

The hardened concrete properties of Normal SCC and GFRSCC mixes such as compressive strength, split tensile strength and flexural strength were studied in this work. The effect of addition of Cem-FIL AntiCrack HD glass fibers on the hardened properties of Normal SCC and GFRSCC were investigated.

\subsubsection{Compressive Strength}

The compressive strength test was performed on the standard cubes made of the Normal SCC and GFRSCC mixes under CTM [17]. Ultimate load upon failure was recorded and corresponding compressive strength was calculated. Fig. 1 shows compressive strength values of Normal SCC and glass fibers added GFRSCC mixes. It indicates increase in strength upon addition of Cem-FIL Anti-Crack High Dispersion glass fibers in normal SCC. For $0.25 \%$ addition, the compressive strength was increased by $2.8 \%$ whereas, $0.50 \%$ addition showed $12.42 \%$ increase in strength as compared to normal SCC.

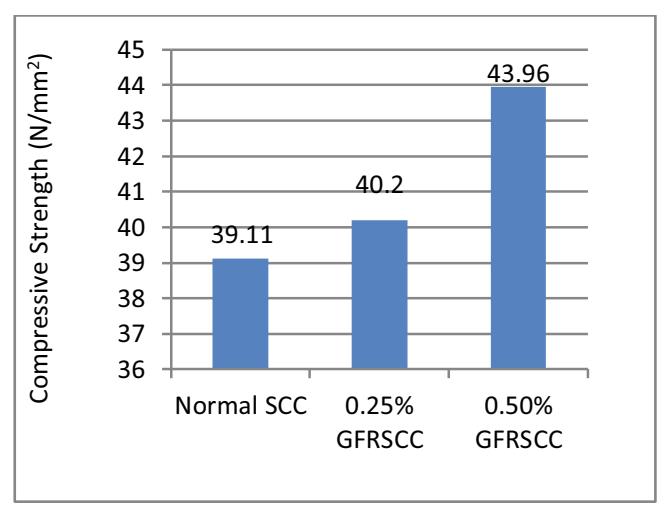

Fig. 1 Compressive Strength Vs \% of Cem-FIL Anti-Crack HD Glass Fibers

\subsubsection{Split Tensile Strength}

The split tensile strength test was performed on the cylindrical specimen cast from Normal SCC and $0.25 \%, 0.50 \%$ fiber added GFRSCC [18]. It was observed that upon addition of $0.25 \%$ and $0.50 \%$ Cem-FIL Anti-Crack High Dispersion glass fibers to $\mathrm{SCC}$, theres is increase in split tensile strength by $4.47 \%$ and $12.25 \%$ respectively. Fig. 2 shows tensile strength values of fiber added GFRSCC mix being more than normal SSC mix.

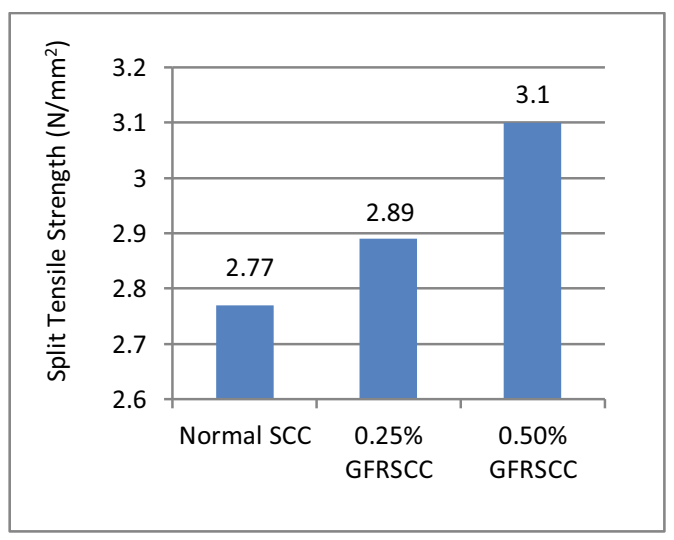

Fig. 2 Split Tensile Strength Vs \% of Cem-FIL Anti-Crack HD Glass Fibers 


\subsubsection{Flexural Strength}

Standard beam specimens were cast to perform flexural strength test for normal SCC and GFRSCC mix. Fig. 3 indicates increase in flexural strength upon addition of Cem-FIL Anti-Crack High Dispersion glass fibers. For $0.25 \%$ fibers addition, strength increased by $6.57 \%$ and for $0.50 \%$ fibers addition, showed maximum increase in flexural strength by $14.34 \%$. Thus, glass fibers addition has made enhancement in hardened properties of SCC mix.

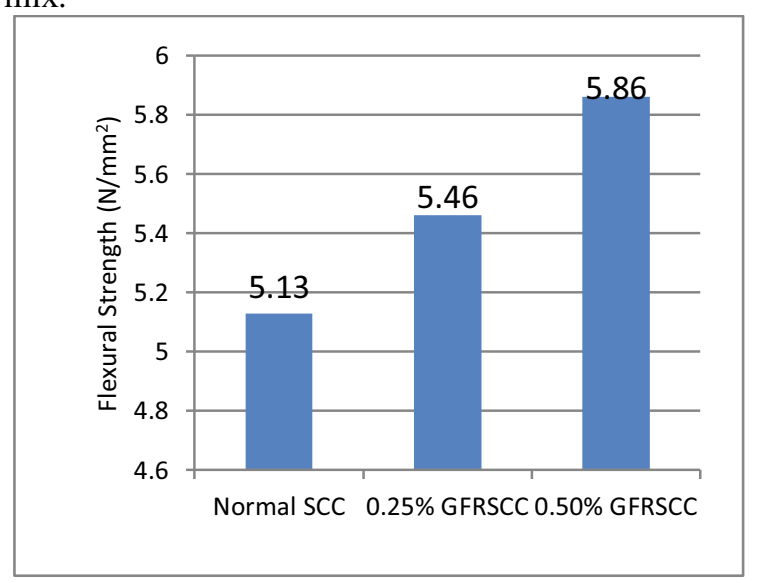

Fig. 3 Flexural Strength Vs \% of Cem-FIL Anti-Crack HD Glass Fibers

\subsubsection{Load Vs Deflection values}

During flexural strength test, the ultimate load corresponding to failure of beam was recorded for normal SCC and GFRSCC beams. The deflection values under applied load were recorded with help of dial gauge. Fig. 4 gives plot of load Vs deflection for normal SCC as well as GFRSCC mix consisting of $0.25 \%$ and $0.50 \%$ fibres addition.

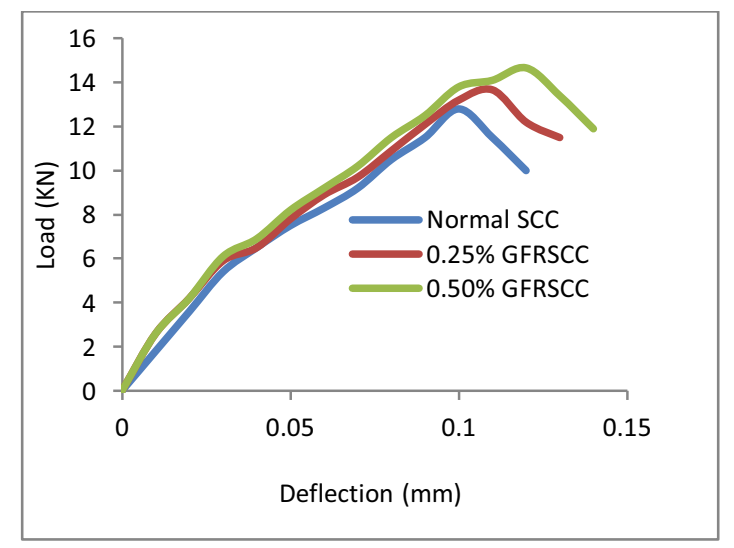

Fig. 4 Load Vs Deflection for Normal SCC Beams

In case of normal SCC mix ultimate load value was found to be $12.824 \mathrm{KN}$ which denoted failure of beam. Thereafter applied load value has decreased and wide cracks were observed at beam bottom. After the addition of Cem-FIL Anti-Crack High Dispersion glass fibers, the load carrying capacity of beams increases compared to Normal SCC beams. Propagation of cracks was observed in these beams which mean the beams shows ductile failure. Also the load carrying capacity of $0.50 \%$ GFRSCC beams was more than $0.25 \%$ GFRSCC beams and Normal SCC beams. Propagation of cracks observed in these beams denotes same ductile failure pattern.

\section{Conclusion}

From past literature investigation and based upon experimental work, normal SCC and Cem-FIL AntiCrack High dispersion glass fibers added as $0.25 \%$ and $0.50 \%$ by weight of total cementitious material contents in GFRSCC mix were prepared. Both mix were investigated for workability test as well as for hardened properties. Following conclusions are drawn based upon results obtained in above investigation:

1. Workability of SCC mix depends upon flow value of fresh concrete mix. Upon addition of glass fiber as $0.25 \%$ and $0.50 \%$ by weight, the workability was found to decrease due to presence of fibers, making concrete mix stiff and difficult to flow. Extra dosage of Superplasticizer is required to make concrete flow through mould while testing.

2. The compressive strength of GFRSCC increases by $2.80 \%$ and $12.42 \%$ due to addition of glass fiber as $0.25 \%$ and $0.50 \%$ by weight, as compared to the compressive strength of Normal SCC. This indicates presence of fibers increase toughness of concrete. Hence preferable for SCC mix.

3. The split tensile strength of GFRSCC increased by $4.47 \%$ and $25.12 \%$ due to addition of glass fiber as $0.25 \%$ and $0.50 \%$ by weight, as compared to the split tensile strength of Normal SCC. Fiber addition has reduced the crack propagation in concrete making it more durable and sustainable for tensile stresses.

4. The flexural strength of SCC increases by $6.57 \%$ and $14.34 \%$ due to addition of glass fiber as $0.25 \%$ and $0.50 \%$ by weight, as compared to the flexural strength of Normal SCC.

5. Load-deflection curve plotted based upon flexural strength test deflection values indicates, concrete failure was gradual under applied load. Fibers addition helps to make concrete ductile and gives prior warning before failure of member.

6. For better and homogeneous mixing of Cem-FIL Anti-Crack High Dispersion glass fibers in the SCC, fibers were added in the wet mix after the addition 
of all ingredients of normal SCC along with Superplasticizer.

\section{References}

1. H. Okamura, Concrete International, 1, 4, pp. 378-383, (1998).

2. T.R. Naik and S. Singh, ACI Materials Journal, 94, 5, pp. 355-360, (1997).

3. H.G. Russell, Concrete International, 19, 8, pp. 62-63, (1997)

4. S. Prashanth, K.M. Subbaya, K. Nithin and S. Sachhidananda, Journal of Material Sciences \& Engineering, 6, 3, (2017).

5. N. Su, K-C Hsu and HW Chai, Cement and Concrete Research, 31, pp. 1799-1807, (2001).

6. J.K. Su, S.W. Cho, C.C. Yang and R. Huang, Journal of Marine Science and Technology, 10,1, pp. 8-13, (2002)

7. T.S. Babu, M.V.S. Rao and D.R. Seshu, Asian Journal of Civil Engineering, 9, 5, pp. 457-472, (2008).

8. M. Chandrasekhar, M.V.S. Rao and M. Janardhana, Proceedings of International Conference on Advances in Materials and Techniques for Infrastructure Development, India, pp. 28-30, (2011).
9. S. L. Hake, R. M Damgir, Global Journal Of Civil Engineering, Knowvel Publication, 01, 1-5, (2019).

10. S. L. Hake, S. A. Urphate, P. R. Awasarmal, R. M Damgir, Global Journal Of Civil Engineering, 01, 12-15, (2019).

11. Sandeep L. Hake P. R. Awasarmal R. M. Damgir Global Journal of Material Science \& Engineering, 01, 13-17, (2019).

12. Sandeep L. Hake, Dr R. M. Damgir, Dr S.V. Patankar, Advances in Civil Engineering Hindawi Publication, (2018).

13. The European Guidelines for Self-Compacting Concrete, EFNARC, (2005).

14. ACI Committee 237: American Concrete Institute, Denver, CO, (2015).

15. IS-10262:2019, Concrete mix proportioningGuidelines, Bureau of Indian Standards, New Delhi, (2019).

16. IS-456:2000, Plain and Reinforced ConcreteCode of Practice, Bureau of Indian Standards, New Delhi, (2000).

17. IS-9103: 1999, Concrete AdmixturesSpecification, Bureau of Indian Standards, New Delhi, (1999) 